\title{
Validation of the Comfort scale for relatives of people in critical states of health ${ }^{1}$
}

\author{
Kátia Santana Freitas ${ }^{2}$ \\ Igor Gomes Menezes ${ }^{3}$ \\ Fernanda Carneiro Mussi ${ }^{4}$
}

Objective: this methodological study aims to present the construct validity of the Comfort scale for family members of people in a critical state of health (ECONF). Method: this is a methodological study. The sample was made up of 274 family members of adults receiving inpatient treatment in six Intensive Care Units (ICU) in the State of Bahía responded to 62 items distributed in 7 dimensions. The validation procedures adopted were based on the techniques of the Classical Test Theory. Results: the analysis of dimensionality was undertaken through principal components analysis, a scale being obtained with 55 items distributed in four factors: Safety, Support, Family member-relative interaction and Integration with oneself and the everyday. The analysis of the items' ${ }^{\prime}$ discriminative power, undertaken by the item-total correlation-coefficient showed a good relationship of the items with their respective factors. From the ECONF's reliability test, from the analysis of internal consistency, a raised Alpha Cronbach coefficient was obtained for the 4 factors and the general measurement. Conclusion: the comfort scale presented satisfactory psychometric parameters, thus constituting the first valid instrument for evaluating the comfort of family members of people in a critical state of health. The advance made by the study lies in its theoretical framework on comfort, and provides the health team with a scale based on empirical evidence.

Descriptors: Psychometrics; Family; Intensive Care Units; Nursing.

\footnotetext{
1 Paper extracted from Doctoral Dissertation "Construction and validation of the scale of comfort to relatives of people in critical state of health (ECONF)", presented to Universidade Federal da Bahia, Salvador, BA, Brazil. Supported by Conselho Nacional de Desenvolvimento Científico e Tecnológico (CNPq), Brazil, process \# 483821/2011.

2 PhD, Adjunct Professor, Departamento de Saúde, Universidade Estadual de Feira de Santana, Feira de Santana, BA, Brazil.

3 PhD, Adjunct Professor, Instituto de Psicologia, Universidade Federal da Bahia, Salvador, BA, Brazil.

${ }^{4} \mathrm{PhD}$, Associate Professor, Escola de Enfermagem, Universidade Federal da Bahia, Salvador, BA, Brazil.
}

Corresponding Author: Kátia Santana Freitas Universidade Estadual de Feira de Santana Departamento de Saúde Av. Transnordestina, $\mathrm{Km} \mathrm{3,} \mathrm{s/n}$ Bairro: Novo Horizonte CEP: 44036-900, Feira de Santana, BA, Brasil E-mail: ksfenfpro@hotmail.com
Copyright $\odot 2015$ Revista Latino-Americana de Enfermagem This is an Open Access article distributed under the terms of the Creative Commons Attribution Non-Commercial License (CC BY-NC).

This license lets others distribute, remix, tweak, and build upon your work non-commercially, and although their new works must also acknowledge you and be non-commercial, they don't have to license their derivative works on the same terms. 


\section{Introduction}

Comfort can be described as a complex, multidimensional construct, as different concepts have been used by researchers in this area to characterize it. When associated with the family members of persons receiving inpatient treatment in ICU, comfort has been related to the hospital environment's infrastructure alone, such as waiting rooms with comfortable chairs and televisions, access to food, drinks, blankets ${ }^{(1)}$. It is understood, however, that promoting comfort goes beyond the environmental sphere, as it results from the family members' interaction with the health practices, the medical-scientific rationality upon which these are based, and the institutional objects, which may be a source of comfort or discomfort ${ }^{(2)}$. In addition to this, the experience of (dis)comfort permeates the position which the hospitalized person occupies in the family context, the evolution of her health condition, and the family's perception of her suffering, as well as the coping strategies used by the family in previous experiences with hospitalization or illness(3).

The recognition of the serious illness's impact on family members of patients with critical health conditions is described in the literature ${ }^{(4-5)}$, but the health professionals' understanding of what it means for the family to feel comforted, and of this phenomenon's multidimensionality, remains limited. As a result, the care practices may not consider the promotion of comfort.

The shortage of Brazilian and international studies on the issue of comfort from the perspective of family members, and its measurement in the context of the ICU, was evident in the literature review made in the LILACS, MEDLINE and CINAHL databases, covering the last ten years and using the uniterms conforto, família, unidade de terapia intensiva, comfort, family, and intensive care unit. Studies were not identified on the measuring of comfort among family members of persons in ICU. Only one investigation proposed the measurement of the comfort of persons caring for people in the terminal phase, which was an adaptation of the General Comfort Questionnaire(6).

Considering these gaps, the defense of the family's comfort as a nursing care goal(7-8) and the evidence of the need for greater knowledge, specifically on comfort, based on the Brazilian family, as well as the lack of appropriate instruments for measuring this, it becomes essential to gain a closer understanding and more accurate measurement of this phenomenon.

In the light of this panorama, the need was identified to construct the Comfort Scale for Family Members of Persons in a Critical State of Health (ECONF), using theoretical and empirical procedures for the development of scales, according to Classical Test Theory $(\mathrm{CTT})^{(9)}$. For the ECONF's content validity study, the first stage of the process of constructing a scale, the following were identified: the meaning, the dimensions and the descriptors of the comfort for each family; the items were developed for each dimension of the construct, and the format of the pilot-instrument and the instructions for applying it were defined.

Once the content validity procedures had been defined, the ECONF was submitted for the study of its psychometric properties, dimensionality and reliability, with a view to its final validation.

Based in the above, this study aimed to validate the Comfort Scale for Family Members of Persons in a Critical State of Health (ECONF).

\section{Methods}

This is a methodological study, undertaken in six ICUs in three large* public hospitals in the State of Bahía.

The participants were members of the families of adults receiving inpatient treatment in ICU, who met the following criteria: to be aged $\geq 18$ years old; to be the person who was closest to the hospitalized family member, who lives with him or her, and who has a close relationship; to have an adult family member in the ICU who had been hospitalized there for over 24 hours; to have visited the member more than once and to be emotionally able to answer the research questions. For the sample calculation, a sample error of $5 \%$ was adopted, and a population of 420 subjects. A total was considered of 210 ICU beds in public hospitals in the cities of Feira de Santana and Salvador, although with the aim of interviewing two family members of one family member in the ICU, the study population was estimated at 420 subjects. After the establishment of these parameters, the sample calculation indicated 246 participants. Nevertheless, a sample was produced of 274 family members, between 07/08/2010 and 11/27/2010.

For data collection, two instruments were used involving interviewing. The first was composed of closed

* In Brazil, a 'large' hospital is defined as one with between 151 and 500 beds. Translator's note. 
questions regarding data concerning the hospitalized member of the family and the other family members' sociodemographic data. The second was the preliminary version of the ECONF, made up of 62 items distributed in the seven dimensions: Safety (14 items), Receptiveness (12 items), Information (12 items), Social and Spiritual Support (04 items), Proximity (04 items), Convenience (07 items), and Integration with Oneself and the Everyday (09 items).

In order to measure the degree of comfort in relation to each item, a graduated Likert-type scale was used, with five response intervals, which varied from 1 - 'not comfortable at all', 2 - 'not very comfortable', 3 'more or less comfortable', 4 - 'very comfortable', and 5 - 'totally comfortable'. The measurement scale rises, that is, the higher the value attributed to the items, the greater is the degree of comfort.

The work was approved by the Research Ethics Committee and met the observations of Resolution $466 / 12$ of the National Health Council. It was approved under protocol CEP: 078/09.

In order to identify the subjects, those people who had been receiving inpatient treatment for over 24 hours, were identified in the ICUs' 24-hourly bed management records, while the family members who met the other inclusion criteria were identified in the waiting room. These were advised regarding the research's objectives and procedures. After signing the Terms of Free and Informed Consent, they were invited to participate in an interview in a private room near the ICU. Interviews were held with no more than two members of each family.

The Statistical Package for the Social Sciences software (SPSS), version 18.0 for the Windows platform, was used for the analysis. The hypothesis test for normality used was the Kolmogorov-Smirnov test, with the asymmetry values and values for the kurtosis of the multivariate distribution also being verified. After the testing of the distribution, 24 outlier cases were excluded, to correct the deviations from normality of the distribution, 250 cases remaining for the analyses. Descriptive statistics were used to describe the characteristics of the family members and the ECONF scores.

For analysis of the dimensionality, principal component analysis (PCA) was used. To evaluate the factorability of the scale, the Kaiser-Meyer-Olkin Measure of Sampling Adequacy (KMO) test was undertaken, which indicates the suitability of the data for the PCA. The closer the value is to 1 , the better the suitability ${ }^{(11)}$. To determine the number of factors to be extracted, the researchers used the criteria of Kaiser (Eigenvalue $>1$ ), Cattell (Scree Plot) and Horn (Parallel Analysis).
The rotation procedure adopted was orthogonal, of the Varimax type. In order to confirm or refute the hypothesis of the construct's unidimensionality, due to the high variance of the first component extracted, a PCA was undertaken, with two factors, Promax oblique rotation, using the Microfact program, using the matrix of polychoric correlations, using the correlation between the two factors as a parameter. The factorial loads were considered significant when they exceeded the absolute value of 0.30 . Items were excluded if they did not present a factorial load in any factor, as were items considered ambiguous because of presenting factorial load in more than one factor where the difference between them was less than 0.10. The items which presented a factorial load in more than one factor, and where the difference between these was greater than 0.10 remained in the factor in which they obtained the highest factorial load ${ }^{(10)}$.

The analysis of the items' discriminative power was carried out by the item-total correlation coefficient (ITC), which aims to measure each item's relationship with its respective dimension. This type of analysis guided the retention or exclusion of an item, in indicating how much it contributed to its dimension. The value of 0.20 was standardized as the minimum value for the exclusion of an item(11). For the test of the scale's internal consistency, the researchers used the factors' and the general measurement's Cronbach Alpha Coefficient, considering one alpha value - of a minimum of 0.70 - for the measurement as a whole and for its dimensions ${ }^{(11)}$. For Horn's parallel analysis, the Stata software was used.

\section{Results}

The mean age of the people in ICU was 55.8 years old $( \pm 19.0)$ and the mean length of hospitalization was 8.2 days $( \pm 8.4)$. The predominant medical diagnosis was clinical $(49.6 \%)$, followed by surgical (39.3\%) and clinical progressing to surgical $(11.1 \%)$. The predominant reasons for hospitalization were: post-operative (33.8\%), cardiac disorder $(20.5 \%)$ and respiratory $(12.0 \%)$; the predominant levels of seriousness were seriously ill but stable and extremely seriously ill (24.0\%) and stable (28.2\%). The majority of family members were female $(75.6 \%)$, with a mean age of 40.6 years old ( \pm 11.9$)$, married/stable relationship (69.2\%), Roman Catholics $(59.2 \%)$, with senior high school completed (33.2\%), economically active (60\%) and with no previous experience of having a family member in ICU (66.4\%). Most were sons/ daughters $(44.8 \%)$ or spouses $(18.4 \%)$ of the hospitalized person, although only $44.8 \%$ lived with that person. The 
interviewee him- or herself was responsible for the family in $41.2 \%$ of the cases. It was most common for the interviewees to originate from cities other than those of the hospitals which were the loci of the study (40\%), followed by Salvador (39.6\%) and Feira de Santana (20.4\%).

\section{Analysis of dimensionality}

The KMO test was 0.858 indicating the suitability of the data for the PCA. The self-value criteria (Eigenvalue $>1$ ) indicated a solution of 16 factors with eigenvalues over 1.0, responding as a set for a total variance percentage of $63 \%$. The analysis showed raised explained variance for dimension 1 , indicating that this new factor, in isolation, represented most of this variance $(22.24 \%)$, which suggested the possibility of the ECONF's unidimensionality. As the explained variance for the first factor was high and distant from the explained variance of the second factor $(6.13 \%)$, the attempt was made to confirm or refute the hypothesis of the construct's unidimensionality. It was found that it was not unidimensional, as there was no strong correlation between the two factors $(r=0.481)$, and that there was not even the predominance of items in the first factor.

The analysis of the Scree Plot showed that up to five factors could be retained, with emphasis on the big difference between the variance of the first factor in relation to the others.

Another criteria adopted to arbitrate on the number of factors to be retained was the Parallel Analysis. It may be observed in Figure 1 that the parallel analysis line cut across the scree factors on the fifth factor; in addition, it was verified that the difference between the eigenvalues of the
PA (Parallel Analysis - mean value of the self-values after 10 replications) and of the PCA was positive. Considering these two criteria, the solution suggested by the Parallel Analysis was that of four factors or borderline five factors.

Bringing together the evidences that the construct was not unidimensional and the structure of four to five factors obtained by the Parallel Analysis and by the Scree plot, the solutions were tested and the researchers undertook the PCA, analyzing the structures of five and four factors. In the analysis of five factors, the confused saturation of the items was observed. For the analysis of four factors, on the other hand, better factorial structure was verified, as there were fewer ambiguous or confused items; in addition, greater theoretical congruence was verified in the four-factor model, in considering that the groupings of the items obtained allowed an understandable and logical interpretation of this new dimensionality by the researchers, taking as a base the whole experience and the knowledge developed in the content validation phase. The PCA resulted in a scale with fewer factors than the seven defined initially in the content validation phase.

In Table 1, it may be observed that the grouping in four factors showed that 45 of the 62 items of the ECONF had factorial load greater than 0.30 in only one factor, suggesting their relevance to the same. Fourteen items had factorial load over 0.30 in more than one factor, and when the difference between the two loads was greater than 0.10 the item remained in the factor in which it obtained the highest factorial load $(43,60,09,10,28$, $24,18,55,37,52)$. Seven items were excluded, as they had factorial loads in two factors with difference lower than $0.10(14,15,48,58)$ and did not obtain a factorial load over 0.30 in any of the factors $(34,61$ and 62).

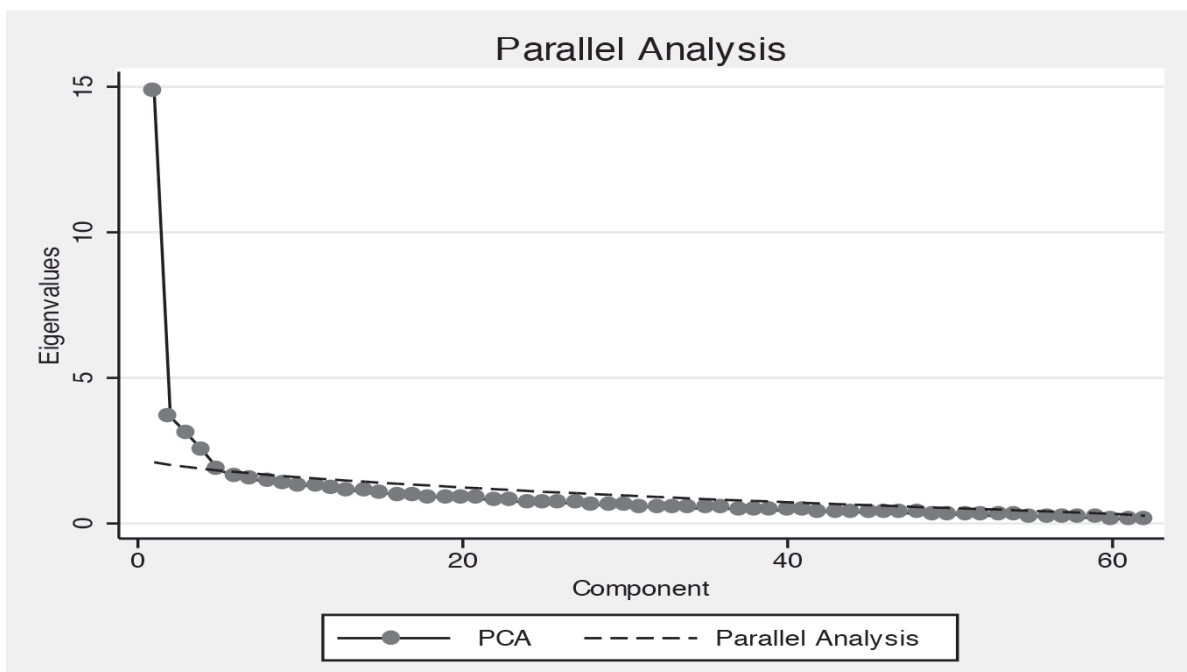

Figure 1 - The items' Parallel Analysis 
In the PCA, the factor 1 grouped 21 items which previously belonged predominantly to the dimension of Safety and Receptiveness, with factorial loads between 0.364 and 0.717 , which showed a good relationship with their factor. Factor 2 grouped items which belonged to the dimensions of information, support and convenience. This factor brought together 20 items, and all presented acceptable values for factorial load. Items 18, 37 and 55 presented factorial loads in factors 1 and 2, remaining in the second due to the greater load in the same, with a difference greater than 0.10 . Factor 3 grouped 7 items which belonged to the domains of safety and proximity, there being a predominance of high factorial loads in the same factor. Factor 4 presented 7 items, with factorial loads which were high and exclusive to this factor, keeping the initial grouping corresponding to the dimension of Interaction with oneself and the everyday (Figure 2). Items 34, 61 and 62 did not present sufficient factorial loads to represent any factor.

\section{Analysis of reliability}

The results of the ECONF's reliability analysis showed that the Cronbach Alpha coefficient $(\alpha)$ remained high for the 55 items, with an excellent value $(\alpha=0.923)$, evidencing the ECONF's high internal consistency.

The analysis of the items' discrimination showed itemtotal correlations (ITC) within the expected parameters, except for items 12 and 35, which were below 0.20. The other items presented expected item-total correlations. In spite of these items presenting borderline correlations, the coefficients were positive, and their exclusion did not cause a considerable increase in the total alpha. It was, therefore, decided to keep them.

The analysis of internal consistency of the four factors which represent the ECONF showed that the factor 1, "Safety", presented a very good $(\alpha=0.89)$ internal consistency, as well as good correlations of its items with the total score of the dimension, which varied from 0.311 (item 21) to 0.670 (item 41). Factor 2 "Support" showed high internal consistency $(\alpha=0.88)$, there being no improvement in this value if any item was excluded. Factor 3, "Interaction between family member and relative" presented satisfactory internal consistency $(\alpha=0.81)$ and the item-total correlations were considered moderate to strong, showing that the items continued to be discriminatory. Factor 4 presented a satisfactory alpha of 0.776 .

Table 1 - Distribution of the items of the ECONF following Principal Components Analysis* for 4 factors. Salvador, State of Bahia, Brazil 2011.

\begin{tabular}{|c|c|c|c|c|c|}
\hline & Items & F 1 & F 2 & F 3 & F 4 \\
\hline 41 & Perceive that the team has patience to listen to the families & .717 & & & \\
\hline 22 & Perceive professional competence in those who work in the ICU & .713 & & & \\
\hline 40 & Know that one's relative is receiving the best care possible & .674 & & & \\
\hline 20 & Perceive that the team pays attention to one's relative's condition & .661 & & & \\
\hline 25 & Feel that the team is interested in one's relative's recovery & .628 & & & \\
\hline 44 & Perceive that one is attended calmly by the team & .624 & & & \\
\hline 47 & Perceive calmness in the attendance given to one's relative & .609 & & & \\
\hline 07 & Know that the ICU offers safety for the recovery of one's relative & .596 & & & \\
\hline 11 & Perceive that the ICU team is happy to offer information & .592 & & & \\
\hline 43 & Perceive that the ICU professionals understand the situation you are experiencing & .533 & .321 & & \\
\hline 60 & Be treated kindly by the ICU professionals & .531 & .325 & & \\
\hline 17 & Have professionals available to help one's relative & .520 & & & \\
\hline 04 & Perceive that one's relative receives care fast when necessary & .510 & & & \\
\hline 09 & Know what treatment is being given to one's relative & .501 & & .308 & \\
\hline 10 & Perceive that one's relative has received hygiene care & .499 & .323 & & \\
\hline 06 & Receive words of support from the team during inpatient treatment in ICU & .469 & & & \\
\hline 45 & Receive information from the professionals in a form that one can understand & .466 & & & \\
\hline 30 & Be attended with respect in the ICU's reception & .465 & & & \\
\hline 14 & Feel that the ICU team is interested in knowing how one is & .456 & .405 & & \\
\hline 28 & Receive detailed information on one's relative's situation & .436 & .326 & & \\
\hline 21 & Perceive that the professionals do not insist on one leaving immediately at the end of the visit & .364 & & & \\
\hline 49 & Have water to drink in the waiting room & & 699 & & \\
\hline 57 & Receive information on how the ICU functions & & 671 & & \\
\hline 36 & Have a public telephone near the waiting room & & 629 & & \\
\hline 38 & Know who the professionals are who can help you if necessary & & .594 & & \\
\hline
\end{tabular}


Table 1 - (continuation)

\begin{tabular}{|c|c|c|c|c|c|}
\hline & Items & F1 & F 2 & F 3 & F 4 \\
\hline 39 & Have comfortable furniture in the ICU waiting room & & .589 & & \\
\hline 24 & See one's relative outside visiting hours when necessary & & .560 & .331 & \\
\hline 18 & Receive information from the doctor every day & .342 & .537 & & \\
\hline 58 & Perceive that the team is interested in whether one is prepared for the visit & .469 & .524 & & \\
\hline 55 & Have a conversation with someone from the team & .355 & .516 & & \\
\hline 33 & Have a means of distraction in the waiting room (magazines, TV, radio) & & .515 & & \\
\hline 13 & Be able to receive information on one's relative when one telephones & & .498 & & \\
\hline 51 & Have a toilet near the waiting room & & .488 & & \\
\hline 23 & Have a waiting room near the ICU & & .481 & & \\
\hline 37 & Receive explanations on what is going to happen with one's relative (transfer, discharge, tests, further treatment) & .323 & .474 & & \\
\hline 19 & Be warned about changes in one's relative's clinical condition at home & & .473 & & \\
\hline 56 & Be allowed to stay in the ICU waiting room outside visiting hours & & .424 & & \\
\hline 50 & Be informed about the reason for the delay of the visit when this occurs & & .420 & & \\
\hline 16 & Be accompanied by a friend or family member during the visit & & .388 & & \\
\hline 15 & Hear the truth from the health professionals concerning one's relative's state of health & .336 & .382 & & \\
\hline 48 & Have friends giving support in this situation & .300 & .351 & & \\
\hline 54 & Receive spiritual/religious support from somebody & & .350 & & \\
\hline 02 & Receive information on one's relative at any time & & .332 & & \\
\hline 31 & Have a place for meals, in the hospital or nearby & & .317 & & \\
\hline 46 & A larger number of visitors allowed when necessary & & .307 & & \\
\hline 62 & Not to receive contradictory information from the ICU professionals & & & & \\
\hline 34 & Believe that faith can help in one's relative's recovery & & & & \\
\hline 61 & Be able to resolve administrative aspects (documentation) of the hospitalization & & & & \\
\hline 32 & Perceive that one's relative is reacting well to the treatment & & & .757 & \\
\hline 08 & See one's relative able to communicate with one & & & .706 & \\
\hline 01 & Perceive that one's relative has a chance of recovering & & & .690 & \\
\hline 52 & See one's relative no longer at risk of dying & & .348 & .663 & \\
\hline 42 & Know that one's relative perceives that one is close by & & & .632 & \\
\hline 03 & Perceive that one's relative likes the treatment he/she receives & & & .562 & \\
\hline 29 & Be able to help one's relative to cope with this situation & & & .444 & \\
\hline 53 & Keep up one's eating habits as prior to the hospitalization of one's relative & & & & .735 \\
\hline 27 & Keep one's routine with one's family members & & & & .727 \\
\hline 26 & Be able to relax and/or distract oneself during the period of hospitalization & & & & 691 \\
\hline 05 & Keep one's sleep routine as prior to the hospitalization of one's relative & & & & 666 \\
\hline 35 & Continue one's habitual activities (study, work, leisure etc.) & & & & 617 \\
\hline 12 & Keep one's emotions under control & & & & .509 \\
\hline 59 & Be physically able to deal with this situation & & & & .450 \\
\hline
\end{tabular}

*ICU: Intensive Care Unit.

\begin{tabular}{|l|c|l|}
\hline Dimensions & N. of items & Items \\
\hline Safety & 20 & $04,06,07,09,10,11,15,18,19,20,23,26,28,37,38,40,41,42,44,55$ \\
\hline Support & 21 & $\begin{array}{l}02,13,14,16,17,21,22,29,31,33,34 \\
35,36,43,45,46,47,50,51,52,53\end{array}$ \\
\hline Interaction Family - relative & 07 & $01,03,08,27,30,39,48$ \\
\hline Integration between Oneself and the Everyday & 07 & $05,12,24,25,32,49,54$ \\
\hline
\end{tabular}

Figure 2 - Distribution of the 55 items of the ECONF in four factors

\section{Discussion}

To measure abstract constructs such as comfort with greater accuracy, it is essential to work with valid, reliable instruments. To this end, techniques and methods for measuring have been used, justifying researchers' concern with psychometric analyses, so as to ensure the validity and reliability of scales $^{(9-11)}$.

This is a pioneering study in regard to the construction of a scale for measuring the comfort of relatives with a family member in ICU. Its originality hinders the comparison of this study's results with 
those of others. The ECONF's construct validity did not confirm the structure with seven theoretical dimensions. Thus, the empirical and analytical procedures allowed a new understanding of the conceptual structure of the construct for these relatives.

Although the analysis of the eigenvalues initially suggested 16 factors, the graphical results of the scree plot and Horn's Parallel Analysis were taken into consideration, indicating a construct of 4 to 5 factors. The explained variance analysis further indicated the predominance of factor 1 in relation to the others, leading to the test of the hypothesis of the construct's unidimensionality, which would go against it being understood as a multidimensional phenomenon, according to specialists on the issue(12). Nevertheless, after this assumption was tested, the ECONF's unidimensionality was refuted; however, this may represent the relevance of the first factor for the explanation of the families' comfort.

Considering this new structure proposed, the first factor came, thus, to be termed Safety, representing the comfort related to the relatives' trust in the health team's technical-scientific competence, as well as to the humanistic competence of the professionals of the hospital institution, which was associated with the consideration of the family as people, and with demonstrations of emotion to them. The first factor grouped the items of the first dimension (Safety) and of the second dimension (Receptiveness), both present in the preliminary theoretical model, showing that safety entails an association between technique and sensitivity. It grouped a further three items which, in the theoretical model, belonged to the dimension of Information. These items did not refer only to the information offered on the hospitalized member's health condition and treatment, but express how these are shared, through understandable and even - kind communication, making it evident that safety is promoted when the information has such characteristics, allowing better receptiveness and understanding of the content by the family ${ }^{(13)}$.

Factor 2 was made up of items which deal with the need for support for the family due to the needs which appear when a member is hospitalized in the ICU. Termed Support, it represented the comfort related to the hospital infrastructure in terms of the physical space for accommodation and meeting the needs of family members in the hospital, and to the flexibility of the hospital norms and routines in relation to the family's needs, especially regarding those related to visiting and the family's access to information in order to know about the health conditions of the hospitalized member. The items on information, which were placed in the second factor, differed qualitatively from those incorporated into the first factor, in that they dealt with the accessing of information by the family, covering content such as: anticipated treatment for the family member in the ICU, the frequency with which information is received, the professional category which provides the information, the place and means of transmission of the information (at home or in hospital, by telephone or personally, among others), the structure and organization of the ICU and changes in the hospital unit's routines and flows.

The items of the Support factor also address the comfort related to the facilities in the waiting room. It is known that due to the restrictive visiting policy in Brazilian ICUs, this room is where the family member spends most of his or her time; there, he or she can feel close and available to accompany what is happening with the relative, and resolve problems as they emerge. It is necessary, therefore, for this place to be pleasant and to have facilities and some resources. It must be spacious, clean, private, close to the ICU, equipped with comfortable furniture, drinking water, toilets, means of distraction and a public telephone. Another aspect described in the items of this factor referred to the availability of a place for meals in the hospital. Such support can prevent the appearance of further discomfort $^{(7-8,14)}$.

The items of factor 3, termed Interaction between family member and relative described the emotional dimension of the relationship between the family member and the hospitalized member. It represented the comfort of being with the member, of benefitting from the interaction established between them, of perceiving the possibility of seeing the patient recover and the patient's satisfaction with the care given. To promote the proximity between them and to ensure the best conditions of care is fundamental for the promotion of comfort to the family. The items of factor 3 also described the comfort associated with the relatives' perception of the chance of the ill family member's recovery, along with the minimization of the possibility of losing him or her, so as to re-initiate relationships as they previously existed in day-to-day life. The illness has 
been experienced collectively, the "incapacitated patient" even if temporarily, is equal to the incapacitated family, even if this last has the ability to re-organize itself(5,14-15).

Factor 4, termed Integration with oneself and the everyday kept the grouping of the seven items in the theoretical model and represented the comfort associated with the possibility of the family member managing to care for him- or herself, to help his or her relative and to give continuity to family life, as happened before the member entered ICU. This factor evidenced the impact of the hospitalization of a member in ICU on the families' life, as has already been observed by some authors ${ }^{(7-8,14-16)}$.

\section{Conclusion}

The ECONF is the first instrument constructed for the evaluation of the comfort of family members of persons in ICU. The scale was tested in a city in the North-East region of Brazil and must be tested in other regions of Brazil, in order to confirm its validity and accuracy as a scale for use in Brazilian families of patients hospitalized in ICU.

It represents an advance through the construction of a theoretical framework on comfort, and makes available to the scientific community a scale based on empirical evidence. The ECONF can help nurses and other health professionals to reflect on and understand the situations of comfort and discomfort experienced by relatives. The results arising from its application will contribute to the proposing and evaluation of the effectiveness of the interdisciplinary care in the promotion of relatives' comfort, favoring the creation of measures of comfort directed at this population.

The results obtained can guide the elaboration of public policies for the promotion of comfort, as well as strengthen the Ministry of Health's policy of humanization for relatives.

Studies on the measuring of comfort remain incipient in our society, above all with relatives; and, based on these results, future research may be undertaken with a view to improving the understanding of the issue and offering support for care practices which aim, effectively, for the promotion of the comfort of members of the family of a person hospitalized in ICU.

\section{References}

1. Hoghaug G, Fagermoen MS, Lerdal A. The visitor's regard of their need for support, comfort, information proximity and assurance in the intensive care unit. Intensive Crit Care Nurs. 2012;28(1):263-8.

2. Mussi FC. Conforto e lógica hospitalar: análise a partir da evolução histórica do conceito conforto na enfermagem. Acta Paul Enferm. 2005;18(1):72-81.

3. Urizzi F, Corrêa AK. Relatives' experience of intensive care: the other side of hospitalization. Rev. Latino-Am. Enfermagem. 2007;15(4):598-604.

4. Hinklea JL, Fitzpatrick E. Needs of American relatives of intensive care patients: Perceptions of relatives, physicians and nurses. Intensive Crit Care Nurs. 2011;27(1):218-25.

5. Siddiqui S, Sheikh F, Kamal R. What families want- an assessment of family expectations in the ICU. Int Arch Med. 2011;4(21):1-5.

6. Novak B, Kolcaba K, Steiner R, Dowd T. Measuring comfort in caregivers and patients during late end-of-life care. Am J Palliative Care. 2001;18(3):170-80.

7. Lourenço EC, Neves EP. As necessidades de cuidado e conforto de visitantes em UTI oncológica: uma proposta fundamentada em dados de pesquisa. Rev Bras Cancerol. 2008;54(3):213-20.

8. Freitas KS, Menezes IG, Mussi FC. Conforto na perspectiva de familiares de pessoas internadas em Unidade de Terapia Intensiva. Texto Contexto Enferm. 2012;21(4):896-904.

9. Pasquali L. Psicometria. Rev EsC Enferm USP. 2009;43(Esp):992-999.

10. Damásio BF. Uso da análise fatorial exploratória em psicologia. Avaliação Psicol. 2012;11(2):213-28.

11. Salmond SS. Evaluating the reliability and validity of measurement instruments. Orthop Nurs. 2008;27(1):28-30.

12. Goodwin M, Sener I, Steiner SH. A Novel Theory for Nursing Education: holistic Comfort. J Holistic Nurs. 2007;25:278-85.

13. Marques RC, Silva MJP, Maia FOM. Comunicação entre profissional de saúde e familiares de pacientes em terapia intensiva. Rev Enferm UERJ. 2009;17(1):91-5.

14. Frizon G, Nascimento ERP, Bertoncello KCG, Martins Jj. Familiares na sala de espera de uma unidade de terapia intensiva: sentimentos revelados. Rev Gaúcha Enferm. 2011;32(1):72-8.

15. Sales CA, Matos PCB, Mendonça DPR, Marcon SS. Cuidar de um familiar com câncer: o impacto no cotidiano de vida do cuidador. Rev Eletr Enferm. [Internet]. 2010 [acesso 9 dez 2011]; 12(4):616-21. Disponível em: http://www.fen.ufg.br/revista/v12/n4/v12n4a04.htm 
16. Horn EV, Tesh A. The effect of critical care hospitalization on family members: stress and responses.

Dimens Crit Care Nurs. 2000;19(4):40-9. 